\title{
APROPRIAÇÃO DE VALOR, RECURSOS E ESTRUTURAS DE GOVERNANÇA
}

APPROPRIATION OF VALUE, RESOURCES AND GOVERNANCE STRUCTURES

Recebido em 25.07.2018. Aprovado em 24.06.2019

Avaliado pelo sistema double blind review

DOI: https://doi.org/10.12712/rpca.v13i2.12619

\section{Sandra Aparecida Brasil \\ sab1605@gmail.com \\ Programa de Pós-graduação em Administração/Universidade Estadual de Maringá - Maringá/Paraná, Brasil \\ ORCID: https://orcid.org/0000-0002-0500-6810}

\section{José Paulo de Souza}

jpsouza@uem.br

Pós-graduação em Administração/Universidade Estadual de Maringá - Maringá/Paraná, Brasil

ORCID: https://orcid.org/0000-0002-5659-1044

\section{Eliana Cunico}

\section{elianacunico@gmail.com}

Programa de Pós-graduação em Administração/Universidade Estadual de Maringá - Maringá/Paraná, Brasil ORCID: https://orcid.org/0000-0002-2707-809X

\section{Resumo}

O estudo visa compreender como a apropriação do valor, gerado por meio de recursos, é influenciada por estruturas de governança estabelecidas por agentes do segmento produtor da Microrregião de Goioerê. Foram realizadas 30 entrevistas com produtores rurais. Os dados foram submetidos à análise de conteúdo, segundo a proposta de Bardin (2009). As análises permitem concluir que com a identificação e proteção de recursos estratégicos a partir de estruturas de governança eficientes, os produtores rurais dispõem de condições para sustentar valor e reduzir custos de transação. Essas estruturas protegem os recursos estratégicos gerados, como tecnologia e ativos humanos, propiciando eficiência.

Palavras-chave: Apropriação de valor. Recursos. Estruturas de governança.

\begin{abstract}
This study aims to understand how the appropriation of value, generated through resources, is influenced by governance structures established by agents of the producer segment of the Microregion of Goioerê. During the survey, 30 interviews with farmers were conducted. The data whose data were submitted to content analysis, according to the proposal of Bardin (2009). The analyzes allow us to conclude that with the identification and protection of strategic resources from efficient governance structures, rural producers have the conditions to sustain value and reduce, because of the specificity of the assets, the transaction costs structures. These structures protect the strategic resources generated, such as technology and human assets, providing efficiency.
\end{abstract}

Keywords: Value appropriation. Resources. Governance structures. 


\section{Introdução}

O setor rural brasileiro tem importante participação no cenário internacional, o que faz o país líder entre aqueles que apresentam os maiores volumes de produção agropecuária (BARBOSA; SANTOS; MACHADO, 2013). O Estado do Paraná configura-se como a quinta maior economia do país (Instituto Paranaense de Desenvolvimento Econômico e Social - IPARDES, 2017a) e destaca-se como o segundo maior produtor de grãos e o primeiro na produção de aves para abate (IPARDES, 2017b). Por sua vez, Microrregião de Goioerê também se destaca, especialmente devido a produção de grãos (soja, milho e trigo) e a criação de animais (bovinos, galináceos, ovinos e suínos), ainda que outras culturas também estejam presentes, como café, feijão e cana de açúcar (IPARDES, 2017c).

A Microrregião de Goioerê tem apresentado especificidades que a diferenciam das demais microrregiões paranaenses, especialmente em função do volume de produção. $\mathrm{O}$ valor bruto nominal da produção ${ }^{1}$ agropecuária do ano de 2010 foi de $\mathrm{R} \$$ 1.108.901.646,92 enquanto em 2013 equivaleu a $\mathrm{R} \$$ 1.885.998.297,33, indicando um aumento de 70\% no período. Três anos após, em 2016, o valor correspondeu a R \$2.655.060.700,33, valor 139\% superior a 2010 (IPARDES, 2015; IPARDES, 2017c).

Além do aumento no volume produzido, foi identificado no mesmo período aumento no valor negociado das terras das unidades produtivas rurais, conforme o Departamento de Economia Rural (DERAL) do Paraná, que apresenta anualmente estimativa do preço $^{2}$ das terras agrícolas por município, tipo de terra e grau de utilização. Conforme DERAL/SEAB (2014), as terras inaproveitáveis tiveram aumento máximo de mais de 2200\%, de 2000 a 2013. Para as terras não passíveis de mecanização, o aumento máximo foi de aproximadamente $1400 \%$ no período. Também no período, as terras mecanizadas apresentaram aumento máximo de mais de $1200 \%$ e as terras não mecanizáveis, o aumento máximo foi de $1500 \%$.

Contudo, apesar do aumento na produção e no valor das terras, a Microrregião de Goioerê tem sofrido redução no número de estabelecimentos (unidades de produção) dedicados à agropecuária. Conforme o Censo Agropecuário 2006-2007³ há, aproximadamente, 82,82\% estabelecimentos a menos do que havia quando da realização do Censo Agropecuário de 1996-1997. O percentual indica redução de aproximadamente 17,18\% em dez anos. Aexceção ocorreu em propriedades com até 1 hectare e entre 200 e 500 hectares.

A microrregião também tem apresentado redução na população rural. O Censo 2000 identificou um contingente populacional de 129.416 habitantes, dos quais 41.743 residiam na zona rural. Já de acordo com o Censo 2010 a população total da referida microrregião decresceu em, aproximadamente, 7,78 \% (passando a ser 116.751 pessoas), e a população rural também decresceu equivalendo a, aproximadamente, 65,55\% do novo total (passando a ser de 27.363 pessoas).

Partindo dessas observações, o objetivo do estudo é compreender quais fatores impactaram no aumento da produção apresentada pela microrregião, apesar de constatado o aumento no valor das terras, a redução no contingente populacional e no número de propriedades rurais. Considerando que tais especificidades podem ter origem nas rendas geradas e na respectiva apropriação indevida das mesmas, em função da forma de gestão da unidade de produção rural, buscou-se a compreensão de mecanismos que sustentem essa realidade.

\footnotetext{
${ }^{1}$ Valor Bruto Nominal ou Valor Bruto da Produção constitui "índice de frequência anual, calculado com base na produção agrícola municipal e nos preços recebidos pelos produtores paranaenses. Engloba produtos da agricultura, da pecuária, da silvicultura, do extrativismo vegetal, da olericultura, da fruticultura, de plantas aromáticas, medicinais e ornamentais, da pesca, etc.", conforme Francisco Simioni (2013), via email.

${ }^{2}$ Os preços apresentados pelo DERAL/SEAB (2015) correspondem a média do hectare informado para fins de pagamento de ITR - Imposto Territorial Rural, não considerando outras variáveis que envolvem a negociação.

${ }^{3}$ Dados referentes ao Censo Agropecuário de 2017, não haviam sido divulgados quando da realização das análises.
} 
Para tanto, utilizou-se da abordagem teórica da Visão Baseada em Recursos (VBR) sob a perspectiva de Barney (1991) e Peteraf (1993), segundo a qual, uma firma alcança desempenho superior (vantagem competitiva) em relação aos concorrentes em função de ganhos ou rendas geradas. Concomitantemente, utilizou-se a teoria da Economia dos Custos de Transação (ECT), sob a perspectiva de Williamson (2012), a partir da qual as escolhas de estruturas de governança tem como finalidade obter ganhos de eficiência, via redução dos custos de transação.

Assim a partir de pressupostos da ECT e da VBR buscou-se por meio da análise dos dados empíricos responder ao seguinte questionamento: Como a apropriação do valor, gerada por meio de recursos, é influenciada pelas estruturas de governança utilizadas por agentes que integram o segmento de produção rural, localizados na Microrregião de Goioerê, no Paraná?

Após a introdução, indica-se o referencial teórico que aborda pressupostos da VBR e da ECT, possibilitando a sustentação teórica à discussão empírica dos dados pesquisados. A seção seguinte apresenta os procedimentos metodológicos adotados para coleta, análise e interpretação dos dados, seguida dos resultados e considerações finais.

\section{FUNDAMENTAÇÃO TEÓRICA}

\section{Visão Baseada em Recursos (VBR)}

Recursos ${ }^{4}$, de acordo com Peteraf (1993), são imputs utilizados no processo produtivo. No modelo da VBR, recursos são ativos tangíveis e intangíveis, definidos como a base para a elaboração de estratégias capazes de permitir Vantagens Competitivas (VC) ou Vantagens Competitivas Sustentáveis (VCS) (BARNEY; HESTERLY, 2011).

Neste sentido, conforme Barney (1991) e Barney e Hesterly (2011), recursos podem ser classificados em: recursos de capital físico (tecnologias, equipamentos, localização geográfica, entre outros); recursos de capital humano (experiência, treinamento, relacionamentos, entre outros); recursos de capital organizacional (comunicação e controle organizacionais, sistemas formais e informais de planejamento, controle e coordenação organizacional, dentre outros); e, recursos financeiros (dinheiro disponível, que pode ser próprio, de acionistas, de bancos, lucros, dentre outros).

Em função dos recursos que a firma dispõe Barney (1991), Peteraf (1993), Peteraf e Barney (2003) e Barney e Hesterly (2011) indicam as premissas fundamentais da VBR: heterogeneidade dos recursos e imobilidade dos recursos. A Heterogeneidade de recursos "significa que, para determinado ramo de atividade, algumas empresas podem ser mais competentes que outras" (BARNEY, HESTERLY, 2011, p. 59). Isso implica que recursos apresentam-se distintos no interior das firmas. Sendo distintos, os recursos possibilitam a criação de estratégias competitivas que conduzem a VCS (BARNEY, 1991). Por outro lado, Barney (1991) refere-se à imobilidade de recursos, pois os mesmos não podem ser transitados entre as firmas, levando a performances distintas.

A heterogeneidade e a imobilidade de recursos, como explicado por Barney (1991), geram vantagens à empresa por meio da criação de barreiras aos concorrentes, decorrentes de vantagens de pioneirismo e barreiras à entrada e mobilidade. Barreiras decorrentes de vantagem de pioneirismo (first-mover advantage) são decorrentes da posição de uma empresa em uma indústria alcançada por meio de acesso primeiro a elementos como matéria-prima, canais de distribuição, reputação positiva, confiança de consumidores (BARNEY, 1991). As barreiras à mobilidade surgem do controle de recursos heterogêneos, o que permite alcançar VCS frente aos concorrentes (BARNEY, 1991).

\footnotetext{
${ }^{4} \mathrm{Na}$ VBR, alguns autores tratam de recursos (BARNEY, 1991), enquanto outros tratam de recursos e capacidades (HELFAT; PETERAF, 2003). Neste estudo, optou-se por adotar o termo recursos.
} 
Neste sentido, uma vantagem competitiva pode ser compreendida como um diferencial positivamente favorável em relação aos concorrentes. Representa segundo Peteraf (1993), ganhos em termos de eficiência, seja pelo alcance de custos menores gerando rendas ricardianas, seja pela possibilidade de obtenção de lucros monopolistas. De acordo com Noll (2005), a renda ricardiana deriva de menores custos de produção e a renda monopolista do exercício de poder de monopólio.

Contudo, segundo Barney (1991), há distinção entre os recursos ${ }^{5}$ que são e que não são capazes de gerar VCS. Uma vantagem competitiva é considerada sustentável, conforme o autor, se as vantagens dela decorrentes perduram mesmo após cessarem os esforços para manutenção da vantagem competitiva. Uma vantagem competitiva não vai "durar para sempre" (last forever), mas perdurar mesmo após os esforços para criá-la e mantê-la não mais existirem. Conforme Bento e Montenegro (2014) para as organizações que possuem tais recursos, o desafio está na capacidade de explorá-los, bem como em mensurar como eles influenciam nos resultados.

\section{Recursos: atributos (Barney) e condições (Peteraf) para vantagens competitivas}

Barney (1991) e Peteraf (1993) indicam características que um recurso necessita apresentar para ser fonte de vantagem competitiva sustentável. Enquanto Peteraf (1993) apresenta os pilares (cornerstones) da vantagem competitiva, Barney (1991) apresenta atributos dos recursos considerados estratégicos e fonte de vantagem competitiva sustentável.

Os atributos $^{6}$ apresentados por Barney (1991) são expostos no modelo VRIO: valioso, raro, imperfeitamente imitável e insubstituível. Um recurso é valioso, conforme o autor, quando permite que a empresa conceba e implemente estratégias que melhorem sua eficiência. Um recurso é raro se não está disponível à todas as empresas, pois como explica Barney (1991), o mesmo não existe simultaneamente em duas firmas concorrentes. Identificar se um recurso é raro, para o autor, implica em avaliar se o mesmo pode ser controlado por muitas firmas, se o for provavelmente não vai ser fonte de vantagem competitiva à nenhuma delas. A imperfeita imitabilidade e a insubstitubilidade impedem que empresas concorrentes possam reproduzi-lo perfeitamente (BARNEY, 1991), ou se sua imitação se apresentar custosa (FOSS, 2005). Para Barney (1991), três razões tornam um recurso imperfeitamente imitável, que separadas ou combinadas conferem à empresa que o controla vantagem sobre as demais: path dependence, ambiguidade causal e recursos socialmente complexos.

Condições históricas únicas, ou path dependence, indicam que uma empresa explora recursos dependendo do modo como está situada no tempo e no espaço, conforme a experiência dos indivíduos no contexto organizacional (BARNEY, 1991). A ambiguidade causal se refere à dificuldade em identificar a ligação entre os recursos controlados pela firma e a vantagem competitiva sustentável, conforme o mesmo autor. Se essa ligação é desconhecida, como explica o autor, outra empresa não terá condições de criar e implementar estratégia de criação de valor alcançando o mesmo tipo de vantagem competitiva. Outra última razão que torna um recurso imperfeitamente imitável refere-se à complexidade social, a qual, de acordo com Barney (1991), consiste em recursos baseados em fenômenos sociais, tais como cultura, relacionamentos interpessoais, que impossibilitam a imitação por outras empresas.

A não substitubilidade é apresentada por Barney (1991) como um quarto atributo. Este consiste no recurso ou no grupo de recursos que não pode ser estrategicamente substituído. Barney (1995) considera a não substitubilidade uma forma de imitabilidade e, Foss (2005) entende que mesmo sendo substituível um recurso pode ainda ser custoso para ser substituído.

\footnotetext{
${ }_{5}^{5}$ Enquanto Barney (1991) menciona que para serem fonte de vantagem competitiva sustentável os recursos devem ser estratégicos, Peteraf (1993) que os mesmos devem ser superiores. Dada que ambos os autores tratam dos mesmos tipos de recursos e dada a imprecisão da terminologia, ambos são utilizados neste estudo.

${ }^{6}$ O modelo VRIO (valioso, raro, imperfeitamente imitável/insubstituível e organização) de Barney e Hesterly (2011) constitui uma concepção aprimorada dos atributos de recursos, de Barney (1991), adotado neste estudo.
} 
Tomando-se como referência a condição do recurso mencionada por Peteraf (1993), quatro fatores devem ser considerados, sendo eles: a heterogeneidade do recurso, a imperfeita mobilidade do recurso, barreiras ex ante e barreiras ex post à competição. A condição de heterogeneidade indica que o recurso apresenta-se distinto (e as vezes único) através das empresas, implicando em ganhos diferenciados àquela que o controla. (PETERAF, 1993). A segunda condição apresentada por Peteraf (1993) consiste nos limites ex-post à competição, que se refere aos limites que decorrem dos recursos heterogêneos, em que as firmas alcançam vantagem em rendas sobre seus concorrentes. E por consequência limites $\boldsymbol{e x}$ post à competição são colocados na medida em que os recursos passam a ser imperfeitamente substituíveis ou imperfeitamente imitáveis.

Para que haja limites expost à competição, a heterogeneidade de recursos precisa ser preservada e a firma detentora dos recursos manter-se em situação superior a seus concorrentes (PETERAF, 1993). A imperfeita mobilidade dos recursos é a condição que ocorre quando os recursos são imperfeitamente móveis, se não podem ser negociados e não tem a mesma utilidade se aplicados por outra firma (PETERAF, 1993). Recursos são também considerados imperfeitamente móveis quando se tornam especializados às necessidades de uma determinada firma, explica a autora.

Foss (2005) e Aragão, Forte e Oliveira (2010) apontam a VBR como uma abordagem contemporânea importante para a análise de VC ou VCS. Entretanto, embora a VBR seja plausível para estudos do campo de Estratégias que propõe discutir competitividade, Foss e Foss (2004) e Augusto e Souza (2015) a apontam como deficiente devido à ausência de uma teoria da firma, indicando para tal o uso de complementaridade com outras teorias, a exemplo da ECT. Ghozzy et al. (2016) sugerem o uso da ECT e da VBR em complementaridade, dado que na relação entre produtor e processador os pressupostos da ECT são mais eficientes, enquanto que nas relações entre processadores e distribuidores, a VBR oferece previsões mais consistentes.

Economia dos Custos de Transação (ECT)Na ótica da Economia dos Custos de Transação (ECT), o estudo da organização econômica tem como ponto de partida a existência de custos de transação. Estes, de acordo com Williamson (2012), diferenciam-se de custos de produção, pois se referem aos custos relacionados a planejamento, monitoramento e a adaptação de tarefas, vinculados a redação, negociação e salvaguarda de um contrato (custos de transação ex-ante) e a fazer cumprir o que foi acordado (custos de transação ex-post).

O estudo da organização econômica, conforme o mesmo autor, pressupõe que o comportamento dos indivíduos pode apresentar duas hipóteses relacionadas a transação, o comportamento oportunista e a racionalidade limitada. Um comportamento oportunista (oportunismo) se refere a busca pela satisfação dos próprios interesses com avidez, o que inclui atitudes como mentiras, trapaça e roubo (WILLIAMSON, 2012). A racionalidade limitada, segundo Azevedo (1997), se refere ao fato de que os agentes não são capazes de prever todas as contingências que envolvem a negociação. Havendo racionalidade limitada, as transações podem apresentar custos adicionais que precisam ser considerados (WILLIAMSON, 2012). Foscaches e Saes (2017, p. 354) atentam que a possibilidade de "bold up ex post é decorrente da racionalidade limitada dos agentes e do comportamento oportunista, que afetará negativamente opções de investimento ex ante".

Os pressupostos comportamentais da ECT (racionalidade limitada e oportunismo) juntamente com os atributos que caracterizam as transações (especificidade do ativo, frequência e incerteza) determinam as condições e os custos envolvidos em cada transação (WILLIAMSON, 1979; 2012). No que se refere a frequência, a transação pode ocorrer de maneira recorrente, ocasional, ou mesmo uma única vez, ou seja, trata do número de vezes em que ela se efetiva. A incerteza, explica o mesmo autor, se refere a distúrbios que podem interferir na transação, desde o mais baixo ao mais alto grau, e cuja origem está em circunstâncias que não são passíveis de previsão, tampouco de controle. De modo complementar, Azevedo (2000) esclarece que a incerteza tem relação com a impossibilidade dos agentes em prever 
acontecimentos futuros. Assim, situações não previstas, podem gerar lacunas que não são passíveis de tratamento contratual, ocasionando perdas ou custos.

Williamson (2012) explica que um ativo é considerado específico dependendo do grau em que pode ou não ser empregado em usos alternativos (reutilizado) sem comprometer seu valor produtivo, as quais são separadas em três classes: (i) não específicos, quando não há investimentos especializados; (ii) mistos, em que há investimentos especializados em nível intermediário; e, (iii) idiossincráticos, em que há investimentos altamente especializados, cuja descontinuidade da transação incorre em perda de valor. Desta maneira, Azevedo (2000) explica que o retorno associado ao uso de um ativo específico depende da continuidade de determinada transação. Ativos específicos podem ser considerados sob seis tipos: ativos físicos, ativos humanos, ativos de marca, ativos dedicados, ativos de local e ativos temporais (WILLIAMSON, 1979, 2012). Ativos físicos são as condições físicas, como matrizes especializadas para a produção de determinados componentes de um produto (WILLIAMSON, 2012). Ativos humanos ou de capital humano constituem os recursos humanos à disposição da empresa, cuja importância passa a ser maior para atividades que requerem que o indivíduo aprenda com a prática (learning by doing) pois uma possível substituição tende a interferir nos níveis de eficiência (WILLIAMSON, 2012). Ativos de marca (especificidade de marca) se refere a reputação ou marca da empresa (WILLIAMSON, 2012).

Já os ativos dedicados constituem investimentos em instalações de modo geral que são direcionadas ao suporte de uma relação comercial em particular e cujos retornos somente existirão se a negociação continuar a existir, explica o autor. Especificidade locacional (especificidade de local) se refere a condição de imobilidade dos ativos, como localização da empresa ou setor próxima ao local de destino ou localização em estágios sequenciais de produção que podem gerar economias em produção e transporte (WILLIAMSON, 2012). Ativo temporal se trata de um tipo de especificidade que depende do fator tempo, como nos casos em a resposta em tempo hábil tem papel vital.

Assim, de acordo com Williamson (2012), a especificidade de ativos alcança maior importância quando associada à racionalidade limitada, comportamento oportunista e incerteza, o que torna as relações mais complexas e mais suscetíveis a perdas. Nesse ponto, as estruturas de governança discutidas a seguir (mercado, híbrido e hierarquia) interferem na eficiência das transações, em função de seu alinhamento com os atributos da transação. Klein, Crawford e Alchian (1978) destacam que a apropriação de quaserenda ${ }^{7}$ pode ocorrer tanto no mercado quanto na hierarquia e que a diferença entre elas incide apenas no fato de que em contratos verticais há maior especificidade do ativo. Sobretudo, mecanismos de mensuração e contratos eficazes são fundamentais na proteção e distribuição de valor.

\section{Estruturas de governança}

No contexto da Economia dos Custos de Transação, conforme a incidência dos atributos de transação e dos pressupostos comportamentais são estabelecidas as estruturas de governança. Assim, segundo Williamson (1979), uma estrutura de governança constitui uma matriz institucional dentro da qual as transações são negociadas e executadas, sendo elas:

- Mercado: se refere a aquisição de bem ou serviço, a qual segundo Williamson (2012), ocorre quando há transações que não são específicas e cuja contratação apresenta-se ocasional e não recorrente. Trata, de acordo com Fagundes (1997), da transferência de propriedade de um bem ou serviço entre agentes.

- Integração vertical (hierarquia): corresponde a integralização de atividades dentro da estrutura da empresa. Esta se justifica quando há presença de ativos altamente específicos (WILLIAMSON, 2012);

\footnotetext{
${ }^{7}$ A quase-renda decorre de uma relação formal, em que, diante de investimentos específicos oriundos de uma das partes e da incompletude contratual, a outra parte pode exigir alterações de termos, diante da ameaça de hold-up, os quais inviabilizam a atividade (KLEIN; CRAWFORD; ALCHIAN, 1978).
} 
- Contratos (formas híbridas): categorizados por Farina (1997) como formais ou informais os contratos, segundo Williamson (2012), apresentam boas características no que se refere a adaptações e também no que se refere à coordenação das atividades. Desta maneira, de modo similar, Klein, Crawford e Alchian (1978) entendem que os contratos apresentam-se como alternativa à integração vertical, por permitirem minimizar efeitos do comportamento oportunista.

De importância relevante, as estruturas de governança são determinantes dos custos de transação para quaisquer tipos de arranjos produtivos. Segundo Azevedo (1997), isso ocorre mediante a escolha entre incentivo e controle. Ou seja, ao optar-se pelo mercado ao invés da integração vertical, diminui-se o incentivo e aumenta-se o controle, implicando que maior controle significa necessariamente menor incentivo (AZEVEDO, 1997).

\section{Geração e apropriação de valor}

Como abordado por Barney (1991) e Peteraf (1993), recursos constituem o elemento central para alcance de vantagem competitiva sustentável, uma vez que podem permitir o alcance de produtos com qualidade superior ou economias no processo produtivo. Segundo Foss (2005), a partir da alocação dos recursos disponíveis ocorre a criação de valor. Argyres e Zenger (2010) definem como "capacidade comparativa", o termo que explica como uma empresa avalia sua capacidade de entregar um produto ou serviço com menor custo, qualidade superior ou características de contratação de terceiros. Nessa perspectiva, as relações bilaterais envolvem tanto a análise das capacidades internas, como os custos de transação presentes ao buscá-las no mercado. É nesse contexto que a relação entre VBR - recursos e capacidades internas - e ECT - definição de melhor estrutura de governança em função de gerar respostas a decisão "make or buy" visando eficiência na economia de curtos - se integra para discutir não apenas a geração, mas também com o valor é distribuído entre as partes.

A presença de recursos a disposição dos agentes, no contexto da VBR, constitui fonte de geração de valor, cuja presença em muitos casos esta relacionada a especificidade de ativos. Ativos específicos tendem a indicar a estrutura de governança adotada para gerir as transações, tendo em vista que a eficiência, no contexto da ECT, resulta do alinhamento entre estruturas de governança e custos de transação. A lógica da escolha da estrutura de governança, conforme Saes e Silveira (1999) indica que a escolha mais eficiente é aquela que permite melhor apropriação do valor gerado.

Dada a criação de valor, surge o problema da apropriação do valor gerado. Segundo Barney (2004), uma maneira de evitar a apropriação do lucro gerado pela firma por um parceiro, depende da efetividade com que os processos gerenciais são desenvolvidos. Por isso, a apropriação de valor está sujeita a existência de comportamento oportunista na relação de (re) distribuição dos ganhos decorrentes do processo de criação. A apropriação indevida de valor, segundo Klein, Crawford e Alchian (1978), é resultado de comportamento oportunista e interfere na distribuição do valor gerado.

A apropriação indevida de valor é, portanto, um forte limitador a continuidade das transações entre diferentes segmentos. Ou seja, diante da possibilidade de comportamento oportunista, a quase-renda é gerada. A quase-renda que, diante de investimentos específicos realizados por uma das partes e da incompletude contratual, a outra parte pode exigir alterações de termos, diante da ameaça de hold-up, inviabilizando a atividade (KLEIN; CRAWFORD; ALCHIAN, 1978). Assim, não apenas como o valor é gerado importa, mas sim como é distribuído entre partes, tornando necessária melhor compreensão sobre as estruturas de governança que sustentam as transações e seu impacto na geração e sustentação de vantagens competitivas. 


\section{Procedimentos metodológicos}

Partindo de um enfoque qualitativo com abordagem descritiva, buscou-se compreender a realidade de produtores rurais da Microrregião de Goioerê, Estado do Paraná. O estudo, nesta perspectiva, foi desenvolvido com dados primários, tendo como referência a percepção dos sujeitos entrevistados, complementados por dados secundários de instituições oficiais, como IPARDES, IBGE e EMATER. Durante a coleta de dados foram desenvolvidas entrevistas com produtores agropecuários de municípios que compõem a Microrregião de Goioerê, expostos no Quadro 1.

Quadro 1-Municípios, número de produtores e tipos de produção principal

\begin{tabular}{|l|c|l|}
\hline & $\begin{array}{c}\text { Número de } \\
\text { produtores }\end{array}$ & \multicolumn{1}{c|}{ Principais tipos de produção } \\
\hline Altamira do Paraná & 3 & Leite, pão, rapadura, bicho-da-seda, doce de leite, frutas \\
\hline Boa Esperança & 1 & Grãos \\
\hline Campina da Lagoa & 1 & Grãos, leite \\
\hline Goioerê & 4 & Grãos, leite, hortaliças, galináceos, suínos \\
\hline Janiópolis & 2 & Grãos \\
\hline Juranda & 6 & Grãos, leite \\
\hline Moreira Sales & 3 & Grãos, mandioca, leite \\
\hline Nova Cantu & 2 & Grãos \\
\hline Quarto Centenário & 2 & Grãos \\
\hline Rancho Alegre D'Oeste & 4 & Grãos, mel \\
\hline Ubiratã & 2 & Grãos, avicultura para abate \\
\hline TOTAL & $\mathbf{3 0}$ & \\
\hline
\end{tabular}

Fonte: elaborado pelos autores.

Os produtores foram selecionados a partir da indicação de cooperativas, instituições locais e de outros produtores, considerando como critérios trabalharem em atividades rurais há mais de cinco anos e terem obtido aumento de produção em dois anos consecutivos, anteriores a pesquisa. Realizadas individualmente, as entrevistas com os produtores se efetivaram em visitas às unidades de produção (propriedades rurais) ou em locais previamente escolhidos pelos mesmos, entre outubro de 2014 e janeiro de 2015. O critério de saturação deu-se com o alcance de convergência de informações por tipo principal de produção, que foram organizados em grupos: Grupo 1 - Avicultura para abate; Grupo 2 - Grãos; Grupo 3 - Pecuária leiteira; e, Grupo 4 - Hortifrutigranjeiros e produtos da agroindústria.

De modo similar, foram realizadas entrevistas com profissionais que atuam na assistência ao segmento produtor, como funcionários de cooperativas da Microrregião de Goioerê e de Secretarias Municipais de Agricultura. Para interpretação e a análise dos dados, utilizou-se de análise de conteúdo, considerandose a proposta de Bardin (2009), no que se refere a categorização de palavras, tendo como base as categorias de análise (apropriação de valor, recursos e estruturas de governança) oriundas do objetivo do estudo e termos entendidos como similares. Para isso, os dados coletados foram tabulados e previamente analisados como o uso de planilhas eletrônicas, nas quais as subcategorias foram controladas e vinculadas às categorias centrais.

\section{Resultados}

Os resultados da pesquisa indicam que a geração e apropriação de valor ocorrem em função das estruturas de governança, propostas por Williamson (1985 adotadas para as propriedades rurais do estudo, mas tem forte influencia dos recursos, nos termos discutidos por Barney (1991) e Peteraf (1993), a que os produtores rurais têm acesso. As características de tais recursos, por sua vez, repercutem na efetividade com que os produtores geram vantagens competitivas e as sustentam.

Quanto as diferenças de rentabilidade entre as firmas, Saes (2009) afirma que estas decorrem da heterogeneidade existente entre elas, assim como da capacidade de criar, reunir e integrar os recursos disponíveis. Assim, o conjunto de recursos propicia a condução das firmas à desempenhos melhores do 
que outras, especialmente em função do mercado de fatores em detrimento do mercado de produtos (BARNEY, 1991; PETERAF, 1993; FOSS, 2005; SAES, 2009; FOSS, STIEGLITZ, 2011; AUGUSTO; SOUZA, 2015).

Nesse sentido, observou-se junto aos entrevistados que, em função de tais recursos, puderam ser obtidas maiores rendas, geradas a partir de melhores níveis de eficiência, o que se relaciona as estruturas de governança estabelecidas. Os principais recursos e estruturas de governança identificados junto aos produtores são apresentados no Quadro 2.

Quadro 2-Estruturas de Governança e Recursos

\begin{tabular}{|c|c|c|}
\hline Produtores por Grupo & $\begin{array}{l}\text { Principais recursos } \\
\text { identificados }\end{array}$ & Principais estruturas de governança identificadas \\
\hline $\begin{array}{l}\text { Grupo 1: } \\
\text { Avicultura para abate }\end{array}$ & $\begin{array}{l}\text { Estrutura física, localização e } \\
\text { manejo. }\end{array}$ & $\begin{array}{l}\text { A montante e a jusante: Híbrida } \\
\text { (integração à indústria processadora) }\end{array}$ \\
\hline \multirow{2}{*}{$\begin{array}{l}\text { Grupo 2: } \\
\text { Grãos }\end{array}$} & \multirow{2}{*}{$\begin{array}{l}\text { Terra, condições climáticas, } \\
\text { tecnologias, relações de } \\
\text { cooperação, localização. }\end{array}$} & A montante: Via mercado e Hierarquia/Integração \\
\hline & & A jusante: Via mercado e Hierarquia/Integração \\
\hline \multirow{2}{*}{$\begin{array}{l}\text { Grupo 3: } \\
\text { Pecuária leiteira }\end{array}$} & \multirow{2}{*}{$\begin{array}{l}\text { Terra, condições climáticas e } \\
\text { manejo. }\end{array}$} & $\begin{array}{l}\text { A montante: Via mercado e Hierarquia/Integração } \\
\text { (algumas ações são identificadas na produção de } \\
\text { alimentos, como silagem e feno, para os animais) }\end{array}$ \\
\hline & & $\begin{array}{l}\text { A jusante: Forma híbrida } \\
\text { (relação contratual com laticínios) }\end{array}$ \\
\hline \multirow[b]{2}{*}{$\begin{array}{l}\text { Grupo } 4 \\
\text { Hortifrutigranjeiros } \\
\text { produtos da agroindústria }\end{array}$} & \multirow[b]{2}{*}{$\begin{array}{l}\text { Terra, condições climáticas e } \\
\text { manejo. }\end{array}$} & A montante: Via mercado e Híbrida \\
\hline & & $\begin{array}{l}\text { A jusante: Via mercado (venda direta ao consumidor) e } \\
\text { Hibrida (contratual para sericultura e PNAE - Programa } \\
\text { Nacional de Alimentação Escolar) }\end{array}$ \\
\hline
\end{tabular}

Fonte: dados da pesquisa.

Especificamente no Grupo 1, quanto aos produtores de aves para abate, a geração de valor decorre da presença de recursos considerados estratégicos ou superiores (estrutura física, localização e manejo), os quais possibilitam o alcance de vantagem competitiva. Estes recursos apresentam-se valiosos conforme atributos apresentados por Barney (1991) e heterogêneos, conforme condições indicadas por Peteraf (1993). A renda gerada decorre de melhorias obtidas na qualidade do lote de aves, representadas pela presença de mais peso e melhor saúde por ave (produtividade). Desta maneira, destaca-se o manejo que se apresenta como heterogêneo e valioso, embora seja passível de imitação ou substituição, pois sendo associado a outros recursos permite a geração de rendas. Isso ocorre porque, conforme Peteraf (1993) e Barney (2011), mesmo um recurso que seja comum, tal como a água, pode fornecer grande valor econômico decorrente dos benefícios percebidos a partir de seu uso e respectivos custos de obtenção.

O valor que é gerado em função da existência de recursos superiores, por meio da continuidade na relação contratual (com a indústria processadora configurando estrutura híbrida) tem gerado retornos para as partes. Dessa forma, ratifica-se que as formas híbridas se apresentam como contratos, formais ou informais, e são, conforme Klein, Crawford e Alchian (1978), propícios a minimização de possíveis efeitos oriundos de comportamento oportunista por uma das partes. Os produtores não identificam empecilhos à apropriação dos ganhos que lhe são de direito. Contudo, a manutenção dos mesmos depende da continuidade da relação e os produtores relataram que melhorias nas instalações e no manejo não se efetivam em curto espaço de tempo, evidenciando o que afirmam Bento e Montenegro (2014), ao referirem-se ao impacto nos resultados. Outro agravante para a manutenção das rendas está na grande variabilidade do custo dos insumos de produção (ex: alta variação do preço daração em função do preço do milho commodity).

Em relação ao Grupo 2, formado pelos produtores de grãos do tipo commodities, o foco está na padronização da produção. O preço pago pela produção é sempre padronizado, pois são definidos com base em bolsas de valores nacionais e internacionais. A busca por gerar valor se fundamenta essencialmente no alcance de maior volume de produção e menor custo (produtividade). Os recursos 
heterogêneos e valiosos para estes produtores são qualidade da terra, condições climáticas, tecnologias, localização e recursos organizacionais (relações de cooperação), embora somente os recursos localização e organizacionais sejam imperfeitamente imitáveis e insubstituíveis. Os recursos de cooperação entre indivíduos com grau de parentesco representam um diferencial para a geração de valor e podem ser compreendidos, seguindo-se o racional de Barney (1991), como dependentes de complexidade social. Além dos implementos e maquinários, a agricultura de precisão se apresenta como um recurso tecnológico em favor do aumento na produção, conforme os entrevistados.

Aos produtores pertencentes ao grupo de produção de grãos, dada a padronização da produção, ganhos obtidos com a redução dos custos, possibilitam rendas ricardianas. Isso ocorre em função da redução nos custos de produção, associados ao uso da estrutura de governança que permite melhor resultado na negociação, dado o envolvimento de cooperativas. Nesse caso, ratifica-se a proposição de que rendas ricardianas são geradas quando há ocorrência de menores custos de produção (NOLL, 2005). Nota-se que, a comercialização é realizada via mercado, atendendo a hipótese de alinhamento de Williamson (1985), predominando o envolvimento de cooperativas atuantes na região. Variações, todavia ocorrem para a efetivação de venda futura, em que a cooperativa faz a intermediação da venda da produção, quando do planejamento da safra, para multinacionais. Os produtores comprometem parte da produção estimada a preço fixo, como forma de assegurar compradores e reembolso dos custos que tiveram. Essa forma de negociação tem constituído alternativa para assegurar a apropriação dos ganhos gerados frente a incertezas existentes na comercialização.

Há ainda a exceção observada junto a dois produtores, P03 e P30, que apresentam estruturas integradas ou hierarquia. A integralização de atividades dentro da estrutura da empresa, conforme explicita Williamson (2012), se justifica na presença de ativos específicos. No caso do produtor P03, há o cultivo das próprias sementes, de soja e trigo, cuja prática vem sendo desenvolvida com o intuito de reduzir custos com este insumo e obter melhora na produtividade (caracterizando ativo específico). O produtor P30 possui infraestrutura para armazenagem e conservação de grãos - silo de armazenagem (ativo altamente específico e dedicado) e por isso consegue vender, via corretora, à multinacionais, obtendo melhor preço. Esses casos indicam, conforme Farina (1997) que por meio da integração vertical, a firma (propriedade rural) internaliza as transações econômicas, tornando-as subordinadas à hierarquia, na qual os custos do monitoramento e os estímulos internos são associados à estrutura organizacional interna.

Nesse contexto destaca-se a presença de cooperativas na coordenação das atividades desenvolvidas pelos produtores, as quais, no grupo de produtores de grãos tem maior participação. Dada a participação das cooperativas nas relações bilaterais estabelecidas pelos agentes produtores, pode-se entender que, por um lado, estas atuam como fornecedores e, por outro, complementam a estrutura de governança utilizada pelo produtor. As cooperativas apresentam-se complementares a estrutura de governança na medida em que sendo, de propriedade dos produtores a ela cooperados, oferece assistência técnica, acesso a tecnologias e informações ao produtor.

Junto aos produtores de leite, integrantes do Grupo 3, observa-se diferença significativa entre os mesmos. Os produtores que obtém rendas superiores dispõem de recursos valiosos e raros (terra, condições climáticas e manejo), seguindo a classificação de Barney (1991), embora os mesmos estejam acessíveis à todos os produtores, apesar de haver dificuldades de acesso a recursos financeiros e a localização geográfica, por parte de alguns. Rendas superiores obtidas pelos produtores que se destacam decorrem da combinação dos recursos disponíveis, mas apresentam forte dependência de trajetória (path dependence). Isso ocorre notadamente no manejo dos animais - devido a exigência temporal para conhecer as especificidades das raças e de cada animal disponível (especificidade humana), atributos destacadas por Williamson (1985).

Para os produtores de leite, os recursos que se destacam estão relacionados ao uso de práticas aprimoradas em associação a animais de boa procedência e insumos de qualidade. $\mathrm{O}$ uso de ordenhas e de resfriadores propiciam maior volume de leite e condições de aumento na quantidade produzida. Uma 
ordenha, por exemplo, se caracteriza como um ativo de elevada especificidade (ativo dedicado na definição de Williamson, 1985), na produção leiteira, pois não pode ser utilizado em outra atividade. Os produtores que conseguem melhorias no manejo do produto, como alimentação diferenciada aos animais e resfriamento do leite na propriedade, conseguem retornos superiores aos dos demais produtores. O alcance de melhor produtividade depende, conforme demonstrado pelos produtores, da qualidade do solo, das condições climáticas e de tecnologias materializadas sob a forma de bons insumos e boas práticas, que constituem os recursos valiosos e raros à disposição dos produtores de leite. As atividades nesse ramo tendem a ser facilitadas quando há a presença de associações de produtores de leite, como indicado pelos produtores entrevistados. Nesta situação, cabe destacar a explicação de Farina (1997), de que vantagens competitivas podem constituir assimetrias em relação aos concorrentes, como informação, diferenciação e vantagem de custo.

Nos casos em que os produtores se identificaram como vinculados a associações, melhorias da qualidade do produto são identificadas por eles, como critérios para a obtenção de melhores preços. Concomitantemente, as associações mediam negociações com laticínios sob o papel de representante dos produtores, barganhando por melhores preços, dada a oferta de quantidade mais elevada pela agregação da produção de vários produtores. Esse aspecto ratifica a proposição de Saes (2009) de que, pela ECT, a busca pela redução de custos de transação gera também melhor coordenação entre os agentes e um melhor uso dos atributos dos recursos disponíveis.

Considerando-se ainda os produtores de leite, tem-se que o valor gerado, resultante do volume produzido, é assegurado via recebimento de maior preço por litro negociado. O preço superior é formado por uma espécie de recompensa ou prêmio (incentivo de alta potência) pelo volume obtido pelo produtor. Como a renda gerada é dependente do volume, o poder de negociação do produtor frente ao laticínio passa a ser maior, quanto melhor a qualidade originária de fatores relacionados ao manejo, a localização geográfica e de acesso a recursos financeiros. Assim, todos os produtores apresentam relação contratual - não formalizada - com laticínios, mas dadas as características de quantidade do leite produzido, alguns se apropriam de maior renda.

No caso dos produtores de hortifrutigranjeiros e produtos da agroindústria, integrantes do Grupo 4, rendas são decorrentes do uso dos recursos disponíveis, ainda que mais limitados, quando comparados a produtores rurais que trabalham em outras atividades. Destaca-se a pequena quantidade de terras disponíveis. Esses, todavia, buscam como forma de geração de valor, a diversificação na produção e atendimento direto das demandas do consumidor final, por meio da oferta de produtos do tipo "feito em casa". Além das características de origem "caseira" que diferenciam a produção desse grupo, um importante recurso são as tecnologias adotadas. Tais tecnologias no segmento produtor da microrregião estudada não se limitam a mecanização das atividades agrícolas, mas se materializam principalmente em técnicas e manejos apropriados (path dependence) praticados diariamente.

A associação entre tais recursos e o alcance de rendas apresenta-se estreitamente relacionada aos fatores humanos e organizacionais disponíveis, pois se trata, em geral, de atividades manuais e de trabalho intenso, que dependem exclusivamente de mão de obra familiar. Os recursos superiores identificados (terra, condições climáticas e manejo) são passíveis de imitação e substituição por outros produtores, não possibilitando a sustentação de vantagem competitiva e, em alguns casos, a própria criação de vantagem. Mas tais recursos dependem e são fortemente influenciados pela incidência de fatores humanos (conhecimentos e experiência) e de fatores organizacionais (relações de cooperação entre familiares e uso exclusivo de mão-de-obra familiar). Neste sentido, destaca-se o que Barney (1991) denomina como complexidade social, que são recursos que tem forte incidência do fator social impossibilitando a respectiva imitação por outra empresa. Assim, para assegurar a apropriação do mesmo, produtores realizam vendas diretas ao consumidor final, evitando negociações bilaterais com agentes como os supermercados. 
A escolha de mecanismos de governança (predominância de estrutura via mercado), pelos produtores de hortifrutigranjeiros e produtos da agroindústria, além de propiciar economias em custos, proporciona aos produtores a geração de renda, que também decorre da presença de recursos superiores. Assim, a montante identificam-se relações com cooperativas e empresas, enquanto que a jusante predominam relações diretas com o consumidor final. Diferenciam-se o caso do produtor de mandioca que vende a produção para farinheiras, o produtor de bicho da seda que atua de forma integrada ao processador e o produtor que tem contrato com programa de merenda escolar (ambos atuam sob a forma de estrutura contratual formalizada).

De acordo com Saes (2009), considerando pressupostos da VBR, a fonte de valor das empresas está no alcance de rendas ricardianas, que decorrem do uso de recursos internos que outras empresas não possuem. Desta maneira, os recursos disponíveis permitem que os produtores alcancem bons níveis de produção, utilizando as tecnologias disponíveise, em alguns casos, com suporte de empresas cooperativas ou empresas particulares.

Nota-se que, a condição do recurso apresenta-se como fundamental para a geração de valor. Contudo, auferir benefício econômico depende não apenas da obtenção, mas também do uso, como explicam Peteraf (1993) e Barney (2011). Nesse sentido, a escolha de mecanismos de governança apresenta-se como mecanismo de suporte a ser utilizado para assegurar geração de valor e para que o mesmo não se dissipe nas negociações. Considerando que a estrutura de governança tende a ser estabelecida com vistas à redução de custos de transação, conforme Williamson (2012), essas escolhas, de acordo com Saes (2009), se originam nas negociações e tendem a permitir ganhos via proteção do valor gerado nas atividades de produção. As estruturas de governança, de modo geral, têm possibilitado aos produtores o alcance de economias de escala e redução de custos gerenciais. Além disso, a vinculação as cooperativas facilita o acesso a recursos e ao uso de tecnologias na produção, e permite que esses desfrutem do poder econômico e contratual que conforme Coase (1960) é exercido por tais instituições.

\section{Considerações finais}

O questionamento que norteou a elaboração da presente pesquisa foi: Como a apropriação do valor, gerada por meio de recursos, é influenciada pelas estruturas de governança utilizadas por agentes que integram o segmento de produção rural, localizados na Microrregião de Goioerê, no Paraná? Com os dados coletados e analisados, duas vertentes puderam ser destacadas: a importância da Microrregião no contexto produtivo paranaense e a importância dos produtores individualmente, enquanto agentes econômicos e gestores das unidades de produção rural.

Por um lado, a Microrregião de Goioerê constitui importante recorte territorial no contexto produtivo paranaense, dadas as características produtivas locais. No que se refere aos recursos, a Microrregião de Goioerê apresenta solos (terras) férteis e trechos que facilitam a mecanização, condições climáticas favoráveis, diversas empresas cooperativas, fontes de água, mata ciliar e reserva legal que contribuem para a conservação ambiental local. A região apresenta, de forma geral, bom posicionamento geográfico e conta com malha rodoviária que facilita a entrada de insumos e o escoamento da produção agrícola.

Todavia, os principais recursos disponíveis aos produtores (terras férteis, boas condições climáticas e boa localização) que podem ser considerados importantes no contexto microrregional, não podem ser categorizados como estratégicos segundo pressupostos da VBR, por não serem capazes de possibilitar alcance de vantagem competitiva sustentável. O fato é que esses podem ser imitados ou substituídos parcial ou totalmente, ainda que combinados a outros recursos venham a ser fundamentais, para os produtores entrevistados, quando associados a outros recursos.

Em termos específicos, no contexto individual, há forte presença de relações de cooperação entre produtores com grau de parentesco - com forte incidência do fator social ou complexidade social. Percebe-se que a geração de valor decorre do uso dos recursos disponíveis. Mas, isso somente pode 
ocorrer dado o estabelecimento de estruturas de governança adequadas às relações estabelecidas pelos agentes produtores, embora predominem relações via mercado, essas se amparam em relações cooperativas e presença de situações de integração e de estruturas híbridas formais e informais.

Como pudemos perceber, a complementaridade entre as vertentes teóricas adotadas para interpretação da realidade é imprescindível. A VBR utilizada isoladamente não se mostraria suficiente para explicar a realidade, por apresentar um olhar interno a firma. O uso concomitante da VBR com a ECT, propicia suporte mais coerente à compreensão da realidade, pois permite um olhar sobre as negociações entre a firma e outros agentes, abarcando um elemento fundamental na geração de valor: a negociação. Essa dinâmica pode ser observada em todos os grupos de produtores analisados no decorrer do estudo.

Em especial, no Grupo 1 o valor gerado decorre dos recursos humanos e organizacionais, especialmente do manejo, dado que a apropriação é assegurada pela estrutura de governança de integração à empresa processadora. Com foco nos investimentos e nas práticas realizadas, em termos de eficiência, pauta-se o aumento da quantidade produzida e a qualidade da produção. Já no Grupo 2, a busca por gerar renda tem como predominância a aplicação dos recursos disponíveis com o propósito constante de aumento no volume de produção, visando maior produtividade com os mesmos recursos. As estruturas híbridas e o mercado são predominantes, muito em função de cooperativas locais.

Quanto aos produtores que integram o Grupo 3, a geração de valor decorre do uso de práticas aprimoradas e de insumos e animais de qualidade. $O$ valor gerado se materializa diante da maior quantidade de leite. Contudo, não se caracteriza como vantagem competitiva, pois os recursos estão acessíveis à todos os produtores, indeferindo o Modelo VRIO. Nesse grupo, os produtores que conseguem renda superior, em função do volume do leite produzido, conseguem incentivos por meio de melhores preços, apesar de todos adotarem mecanismos de governança via relações contratuais (formas híbridas). Finalmente, no Grupo 4, o valor decorre da diversificação da produção associadas aos recursos disponíveis, ainda que as condições climáticas constituam o único recurso capaz de sustentar vantagens competitivas. Quanto aos produtores que vendem a produção, via estrutura de governança tipo mercado, infere-se que esses agregam valor ao produto por meio das especificidades de mão de obra e das características de produto do "tipo caseiro".

Diante da análise, identificou-se que os mecanismos de governança utilizados pelos produtores são adotados com a perspectiva de permitir a apropriação do valor gerado. As estruturas de governança, por outro lado, contribuem para geração de valor na medida em que auxiliam para que custos de transação sejam reduzidos. Isso porque, a estrutura via mercado é utilizada principalmente pelos produtores commodities, dada a padronização da produção e importância do fator volume de produção na geração de rendas. A estrutura de governança via mercado também é utilizada pelos produtores de hortifrutigranjeiros e produtos da agroindústria, pois estes vendem sua produção diretamente ao consumidor final, e assim não necessitam dividir o valor gerado com agentes varejistas. Em oposto, a estrutura de governança do tipo integração vertical (hierarquia) é utilizada por produtores que buscam eliminar custos de negociação e transação, que foi o caso da produção de sementes de alface (Grupo 3), da produção de sementes de soja (Grupo 2) e da armazenagem de grãos (Grupo 2). Estes produtores, conforme foi identificado, auferem maiores rendas dada a integração e por consequência asseguram a apropriação da mesma, evitando perdas decorrentes da presença de comportamento oportunista.

Formas híbridas são utilizadas principalmente em duas situações - a integração ao processador e a relação contratual como forma de assegurar a venda da produção e preço mínimo para custeá-la. Os produtores integrados à empresa processadora utilizam essa forma de governança por se tratar da opção adotada pela empresa processadora. Além disso, dada a distância de outros processadores torna-se inviável buscála via mercado ou arriscar a produção sem demanda garantida. Por isso essa forma de governança mostrou-se como a mais adequada para assegurar a apropriação do valor gerado. Assim, a escolha do mecanismo de governança configura-se como meio de geração de valor e também de proteção. As 
estruturas de governança estabelecidas asseguram a apropriação do valor gerado a partir dos recursos disponíveis ao mesmo tempo em que permitem também geração de valor via economia em custos de transação.

Diante dos estudos realizados, tem-se que a busca por maior eficiência na comercialização por parte dos produtores rurais (economia em custos de transação), direciona a escolha da estrutura de governança mais adequada para gerir a transação. No entanto, o principal achado deste estudo, que pode contribuir para futuros estudos na área, está no fato de que recursos estratégicos conforme os modelos de Barney e Peteraf são raros de serem encontrados. Mas, a soma dos recursos disponíveis e que apresentem algumas das características do modelo proposto pelos referidos autores possibilita o alcance de vantagem competitiva frente aos concorrentes.

Neste sentido, percebeu-se que a aplicação dos pressupostos teóricos em dados oriundos da realidade geram discrepâncias, devido a dinâmica e volatilidade da realidade e as especificidades das relações contratuais e dos recursos que os produtores rurais dispõem. Dadas as lacunas identificadas entre teoria e prática, observou-se a necessidade de que em próximas pesquisas busque-se considerar a relação entre estruturas de governança e valor gerado, incluindo atributos de mensuração. A proposta pode contemplar a relação entre a especificidade do ativo e a possibilidade de mensuração do valor gerado a cada transação, em função das estruturas adotadas e das possibilidades de proteção dos recursos, a fim de torná-los estratégicos e capazes de permitir VCS.

\section{Referências}

ARAGÃO, L.A.; FORTE, S.H.A.C.; OLIVEIRA, O. V. Visão Baseada em Recursos e Capacidades Dinâmicas no contexto brasileiro: a produção e a evolução acadêmica em dez anos de contribuições.

Revista Eletrônica de Administração - REAd, edição 66, v.16, n. 2 maio/agosto, 2010, p. 373-396.

ARGYRES, N.; ZENGER, T. Capabilities, Transaction Costs, and Firm Boundaries: a dynamic perspective and integration. Atlanta Competitive Advantage Conference Paper, 2010.

AUGUSTO, C.A.; SOUZA, J. P. Transaction Costs Economics and Resource-based View: complementary aspects in the treatment of governance structures. Revista Brasileira de Estratégia, v. 8, n. 2, p. 173-193, may/aug, 2015.

AZEVEDO, P. F. Economia dos Custos de Transação. In: FARINA, E. M. M. Q. et. al.

Competitividade: Mercado, estado e organizações. Capítulo 3. São Paulo: Editora Singular, 1997, 286p.

Nova Economia Institucional: referencial geral e aplicações para a agricultura.

In: Agricultura. V. 47. São Paulo/SP: 2000, p. 33-52.

BARBOSA, R. D. A.; SANTOS, G. T. D.; MACHADO, A. G. C. Estratégias de inovação no agronegócio à luz da RBV: o caso Embrapa Algodão. In: Simpoi - XVI Simpósio de Administração, Logística e Operações Internacionais. 2013. Anais... Disponível:

http://www.simpoi.fgvsp.br/arquvo/2013/artigos/E2013_T00195_PCN76135.pdf. Acesso: 29/09/2013.

BARDIN, L. Análise de Conteúdo. Lisboa, Portugal: LDA, 2009. Ment, Vol 17, 1991.

BARNEY, J. Firm resources and sustained competitive advantage. Journal of Magangement. 1991, p. 99-120. Disponível:

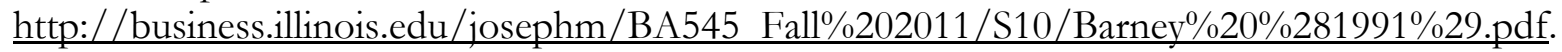

Acesso: 21/07/2013. 
Looking inside for competitive advantage. The Academy of Management

Executive. Vol. 9, N. 4, 1995. Disponível: http://old.ccer.edu.cn/download/7875-1.pdf. Acesso: 24/08/2014.

Capabilities, business processes, and competitive advantage: choosing the dependent variable in empirical tests of the Resource-based View. In: Strategic Management Journal. Vol. 25. 2004.

BARNEY, J. B.; HESTERLY, W. S. Administração estratégica e vantagem competitiva. Trad.: Midori Yamamoto. 3 ed. São Paulo: Pearson Prentice Hall, 2011.

BENTO, C. S.; MONTENEGRO, L. M. Estratégia como Prática e VBR: uma Articulação Teórica. Revista Pensamento Contemporâneo em Administração. Rio de Janeiro, v. 9, n. 1. jan./mar. 2015, p. 159-175. Disponível em:< http://www.uff.br/pae/index.php/pca/article/view/499>. Acesso em: 20/06/2018.

DERAL/SEAB - DEPARTAMENTO DE ECONOMIA RURAL/SECRETARIA DE AGRICULTURA E ABASTECIMENTO. Preços de terras agrícolas - por município e tipo de solo - 2004 a 2014 (Em R\$/há). 2014. Disponível:

http://www.agricultura.pr.gov.br/arquivos/File/deral/terras_pdf_publicacao.pdf. Acesso: 28/03/2015.

Pesquisa de preços - terras agrícolas. 2015. Disponível:

http://www.agricultura.pr.gov.br/arquivos/File/deral/terras_metodologia.pdf. Acesso em 28/03/2015.

FAGUNDES, J. Economia Institucional: custos de transação e impactos sobre política de defesa da concorrência. 1997. Disponível:

http://www.ie.ufrj.br/grc/pdfs/custos_de_transacao_e_impactos_sobre_politica_de_defesa_da_conc orrencia.pdf. Acesso: 05/12/2013.

FARINA, E. M. M. Q. Regulamentação, política antitruste e política industrial. In: FARINA, E. M. M. Q. et. al. Competitividade: Mercado, estado e organizações. Capítulo 4. São Paulo: Editora Singular.1997.

FOSCACHES, C.; SAES, M.S.M. Economia dos Custos de Transação e Teoria da Identidade: um estudo bibliométrico. Desafio Online, Campo Grande, v.5 (3), p. 353-365, Set./Dez. 2017.

FOSS, K.; FOSS, N. J. The Next Step in the Evolution of the VBR: Integration with Transaction Cost Economics. Management Review, Mering, v. 15, n. 1, p. 107-121, 2004.

FOSS, N. J. The resource-based view: aligning strategy and competitive equilibrium. In: Strategy,

Economic Organization, and the knowledge economy: the coordination of firms and resources. Capítulo 3. Oxford Scholarship, 2005.

FOSS, N. J.; STIEGLITZ, N. Modern Resource-Based Theory(ies). Prepared for Michael Dietrich and Jackie Krafft (orgs.), Handbook on the Economics and Theory of the Firm, Edward Elgar, 2011.

GHOZZY, H.; SOREGAROLI, C.; BOCCALETTI, S.; SAUVÉE, L. Impacts of non-GMO standards on poultry supply chain governance: transaction cost approach $v$ resource based view. Supply Chain Management: An International Journal. Vol. 21 (6), p.743-758, 2016.

HELFAT, C. E.; PETERAF, M. A. The dynamic resource-based view capability lifecycles. In: Strategic Management Journal, 24, pp. 997-1010, 2003. 
IBGE. Censo Agropecuário. Instituto Brasileiro de Geografia Estatística. 1996.

Censo Agropecuário. Instituto Brasileiro de Geografia Estatística. 2006.

Censo Demográfico. Instituto Brasileiro de Geografia Estatística. 2000.

Censo Demográfico. Instituto Brasileiro de Geografia Estatística. 2010.

IPARDES - INSTITUTO PARANAENSE DE DESENVOLVIMENTO ECONÔMICO E

SOCIAL. Paraná em números: apresentação. 2017a. Disponível:

http://www.ipardes.pr.gov.br/pr_numeros/index_pr_numeros_pt.htm. Acesso: 12/03/2017.

Paraná em números: atividades econômicas. 2017b. Disponível:

http://www.ipardes.pr.gov.br/pr_numeros/index_pr_numeros_pt.htm. Acesso: 12/03/2017.

Perfil da Microrregião Geográfica de Goioerê. 2015. Disponível:

http://www.ipardes.gov.br/perfil_municipal/MontaPerfil.php?codlocal=604\&btOk=ok. Acesso: 10/04/2015.

Perfil da Microrregião Geográfica de Goioerê. 2017c. Disponível:

http://www.ipardes.gov.br/perfil_municipal/MontaPerfil.php?codlocal=604\&btOk=ok. Acesso: $16 / 03 / 2018$.

KLEIN, B.; CRAWFORD, R. G.; ALCHIAN, A. A. Vertical integration, appropriable rents, and the competitive contracting process. 1978.

NOLL, R.G. Buyer Power and Economic Policy. Standford Institute for Economic Policy Research, 2005. Disponível: http://www.ftp.repec.org/opt/ReDIF/RePEc/sip/04-008.pdf. Acesso:

$21 / 07 / 2014$.

PETERAF, M. A. The cornerstones of competitive advantage: a resource-based view. Strategic Management Journal. Vol 14, N 3, 1993. Disponível em: <

https://business.illinois.edu/josephm/BA545_Fall\%202015/Peteraf\%20(1993).pdf>.

PETERAF, M. A.; BARNEY, J.B. Unraveling the Resource-Based Tangle. Managerial and Decision Economics. ABI/INFORM Global. Vol. 24, N 4, Jun/2003. Disponível em:<

https://www.jstor.org/stable/30035608?seq=1\#page_scan_tab_contents $>$.

SAES, M. S. M. Estratégias de diferenciação e apropriação da quase-renda na agricultura: a produção de pequena escala. 1. Ed. São Paulo: Annablume, FAPESP, 2009.

SAES, M. S. M.; SILVEIRA, R. L. F. O agribusiness do café no Brasil. IPEA/PENSA: 1999.

WILLIAMSON, O. E. Markets, hierarchies, and the modern corporation: an unfolding perspective. 1979. In: Journal of Economic Behavior and Organization. North-Holland, Vol. 17. Disponível em:< https://econpapers.repec.org/article/ucpjlawec/v_3a22_3ay_3a1979_3ai_3a2_3ap_3a233-61.htm>. (1985). As instituições econômicas do capitalismo. São Paulo: Pezco Editora, 2012. Vários tradutores e revisores. 